\title{
Establishing a medical home for patients with inflammatory bowel diseases: a qualitative study
}

\author{
Ksenia Gorbenko, ${ }^{1,2,3}$ Eliezer Mendelev, ${ }^{4}$ Marla Dubinsky, ${ }^{5}$ Laurie Keefer ${ }^{3,5}$ \\ ${ }^{1}$ Population Health Science \& Policy, Icahn School of Medicine at Mount Sinai; ${ }^{2}$ Institute for Health Care Delivery Science, Mount \\ Sinai Health System; ${ }^{3}$ Susan and Leonard Feinstein IBD Center, Mount Sinai Hospital; ${ }^{4}$ New York University School of Medicine; \\ ${ }^{5}$ Division of Gastroenterology, Mount Sinai Health System, New York, USA
}

\begin{abstract}
The Patient-Centered Medical Home model has gained popularity in primary care to provide early effective care to patients with chronic conditions. Prior research on specialty medical homes has been cross-sectional and focused on patient outcomes. The objective of this longitudinal qualitative study was to identify best practices in establishing a specialty medical home in Inflammatory Bowel Diseases (IBD Home). The multimethod study included direct observations of multidisciplinary team meetings ( 30 hours over one year) and in-depth interviews with individual team members $(\mathrm{N}=11)$ and referring physicians $(\mathrm{N}=6)$ around their participation in the IBD home. All interviews were professionally transcribed verbatim. Two researchers coded transcripts for themes using NVivo software. Weekly team meetings $(\mathrm{N}=9 \pm 3)$ included behavioral health providers, nurse practitioners, nurses, dietitians, a clinical pharmacist, and clinical coordinators. Physicians referred patients with psychosocial comorbidities to the IBD home. Initially the team enrolled all referred patients. Later, they developed exclusion criteria and a patient complexity score to manage the volume. Some providers reported increase in their workload (social work, nutrition) while others' workload was unaffected (gastroenterology, nursing). No physicians attended team meetings regularly. Regular in-person meetings helped to strengthen the team. Involving physicians as consultants on an ad hoc basis without regular meeting attendance empowered other team members to take ownership of the IBD Home.
\end{abstract}

\section{Introduction}

Healthcare systems are increasingly adopting interprofessional collaborations that harness the range of expertise

Correspondence: Ksenia Gorbenko, One Gustave L. Levy Place, Box 1077, New York, NY 10029, USA.

Tel.: +1 (212) 659-9387.

E-mail: ksenia.gorbenko@mssm.edu

Key words: Multidisciplinary team; specialty medical home; qualitative methods; team-based care; patient-centered practice.

Presentation: We presented an earlier version of this study as a poster at the Academy Health Annual Research Meeting in 2018.

Conflict of interest:Dr. Gorbenko was co-investigator on educational grants from Pfizer and Abbvie, outside the submitted work. Mr. Mendelev has no conflicts to declare. Dr. Dubinsky reports equity ownership/ is co-Founder of Trellus Health Inc. She has a patent pending for "The GRITT Method", licensed to Trellus Health. Dr. Keefer reports equity ownership/is co-Founder of Trellus Health Inc. She receives personal fees from Pfizer, has a grant from Abbvie, outside the submitted work. In addition, Dr. Keefer has a patent pending for "The GRITT Method", licensed to Trellus Health.

Acknowledgments: We thank GRITTTM-IBD Team who welcomed the researchers and graciously shared their time with us.

Received for publication: 7 January 2020.

Accepted for publication: 9 September 2020.

This work is licensed under a Creative Commons Attribution NonCommercial 4.0 License (CC BY-NC 4.0).

${ }^{\circ}$ Copyright: the Author(s), 2020

Licensee PAGEPress, Italy

Qualitative Research in Medicine \& Healthcare 2020; 4:75-82

doi:10.4081/qrmh.2020.8801 and skillsets of medical and social care professionals to provide high quality and effective care. ${ }^{1}$ One of the primary settings for this model of healthcare is the PatientCentered Medical Home (PCMH), where patients can receive more coordinated and higher quality multidisciplinary care. ${ }^{2}$ The PCMH model for primary care was supported by the Patient Protection and Affordable Care Act of 2010 and a number of professional organizations including the American College of Physicians, resulting in widespread reform of primary care delivery. ${ }^{3}$ A number of studies have evaluated PCMH from the health care provider perspective. ${ }^{4-7}$ For example, attending physicians and residents reported improvements in care coordination, quality and safety of care after the introduction of PCMH but also highlighted inadequate staffing and clinic hours. ${ }^{6}$ Another study found that nurse care coordinators were the single most valuable element of a payer-based PCMH while the online data portal was the least valuable. ${ }^{4}$

Specialist practice reform has lagged, resulting in the development of the analogous patient-centered specialty practice model by The National Committee for Quality Assurance (NCQA) in March 2013. ${ }^{8}$ The NSQA standards largely aim to improve care coordination between primary and specialty practice as well as between specialty practices. ${ }^{8}$ Prior research has explored the adoption of the medical home model in a wide range of specialties including radiology, urology and gastroenterology. ${ }^{9-11}$ There is growing evidence that a Specialty Medical Home (SMH) can improve clinical efficacy, quality of care, and help reduce avoidable Emergency Department (ED) visits, hospitalizations, and procedures, ${ }^{12-16}$ including in the context 
of Inflammatory Bowel Diseases (IBD). ${ }^{17-20}$ Most studies have used cross-sectional design and focused on patient outcomes.

The PCMH and SMH models demand successful inter-practice coordination, which means, for example, that a primary care practice works together with a specialty practice to coordinate care delivery for particular patients who receive care from both types of providers. However, this coordination of care also happens within each practice through interprofessional work between different kinds of providers: physicians, nurses, dietitians, social workers, etc. Effective teamwork within the multidisciplinary teams that make up PCMH and SMH models has been shown to significantly improve clinic efficiency and patient safety. ${ }^{21}$ However, creating an effective team is challenging. Healthcare professionals rarely collaborate with other health care disciplines during formative training (e.g. physicians-in-training rarely work with dietitians-in-training) ${ }^{22}$ Healthcare is structurally hierarchical, which can result in allied health professionals "elbowing" to defend their scope of practice and secure their position within the hierarchy. This behavior undermines collaboration and communication between health professionals. ${ }^{1}$ Few practices allow protected time for inter-professional collaboration, such as dedicated time for multidisciplinary team meetings, despite this factor being critical for getting a holistic view of the patient and their needs. ${ }^{23}$ Our study studied the process of establishing an SMH over a one year period in order to identify best practices.

\section{Methods}

\section{Setting}

This study took place at the Susan and Leonard Feinstein Clinical IBD Center, which is part of the Icahn School of Medicine at Mount Sinai and the Mount Sinai Health System in New York City. The Medical School is a unique setting for IBD as it has been on the forefront of research, identification, and treatment of gastrointestinal (GI) illness since the division's early days. An outpatient clinic was founded and devoted solely to GI diseases in the early 20th century. The IBD Center gastroenterologists cared for 7,500 unique patients with IBD in 2017 alone. Gastroenterologists from throughout the state area send their most challenging cases to the IBD physicians. The Center features personalized treatments, innovative strategies in disease management and the opportunity to participate in clinical trials. The centralized location of the IBD Center enables extensive collaboration among pediatric gastroenterologists, adult gastroenterologists, surgeons, and allied health professionals and delivery of comprehensive care. The program we examined is called Gaining Resilience Through Transitions in Inflammatory Bowel Diseases, or GRITT ${ }^{\mathrm{TM}}-\mathrm{IBD}$, and is an SMH providing team-based multidisciplinary care for pediatric and adult patients with IBD with multiple and complex needs. Here and below we use the terms "IBD Home" and "GRITT" interchangeably. IBD Home patients receive fully integrated medical, behavioral, and nutritional care, which is collocated and delivered at the point of service within an academic IBD Clinical Center. The IBD Home team consists of non-physician providers: a psychologist, social workers, registered dietitians, a clinical pharmacist, nurse practitioners, nurses, a population health coordinator, a child life specialist, and a clinical coordinator. In a separate article, we describe the role of physicians in this program that we found to be that of advisors rather than leaders of the multidisciplinary team..$^{24} \mathrm{By}$ the end of the second year, the program had over 150 patients enrolled in high-touch care, with about half as many having graduated from the program. Program for Protection of Human Subjects at the Icahn School of Medicine at Mount Sinai approved the protocol of the study (IRB-17-02423).

\section{Study Design}

This multimethod study includes two components: i) observations of team meetings by two observers, [KG and EM] (approximately 30 observation hours per year); ii) semi-structured interviews with GRITT team members and referring gastroenterologists.

\section{Data Collection}

Observations. One or two observers [KG and EM] attended GRITT meetings on a weekly basis in 2017-2018. We introduced the study to the team and secured team members' verbal consent to take notes during their discussions. We also informed the team that they could declare any part of the conversation "off the record" at any given point in time, and it would not be recorded or otherwise reported. When a new member joined the team, we reintroduced the study and secured the new member's consent. Observers were taking handwritten or typed notes. We followed a loose observation schedule found in Table 1, and took note of any questions that arose during our observations. Both observers had independent meetings with the team leader (LK) and used these meetings to clarify any new developments or decisions made in the group.

Qualitative interviews. Two authors [KG and LK] developed the initial interview guide that focused on five major topics: i) start of the program; ii) current state of the program; iii) decision making about team processes; iv) patient stories - successes and challenges; v) impact on provider wellbeing (resilience, burnout, coping). Table 2 includes examples of questions we asked in each domain. Two researchers [KG and EM] conducted all interviews. The interviews lasted approximately $30 \mathrm{~min}-$ utes on average and were audio-recorded with participants' permission and later professionally transcribed verbatim. Before each interview, we informed each participant that LK, who is the supervisor for some 
members of the team and the team lead, would be blinded from the interview data and would only see the results of the analysis with no identifying information. After the initial round of interviews with the GRITT team members were over, two interviewers used a shortened interview guide to interview gastroenterologists at the IBD Center who did not participate in the weekly GRITT meetings (Table 3).

\section{Analysis}

Two analysts [KG and EM] read all meeting notes to identify descriptive information, e.g. number of attendees, number of patients discussed and scored, decisions about the program and processes made over the year. The two analysts also coded all the interview transcripts. First, the analysts coded one transcripts per week independently using the comment function of the word-pro- cessing program, creating and applying codes to excerpts of data (open coding approach). The analysts met weekly to discuss coded interviews and come to agreement on codes and their definitions for three weeks. The researchers reviewed any disparities to ensure that the analysis was consistent across analysts. As a result of these discussions, we deemed some codes to be too specific and combined them with other codes (e.g. "EMR challenges" became "EMR" because there was very little data related to this topic). On the other hand, we also found some codes that were too general that needed to be split (e.g. code "communication" evolved into "team communication", distinct from "team meeting" and "team composition"). Our team was able to reach Cohen's kappa of 0.70 after three rounds of coding and discussion. After the first two interviews were discussed, the analysts used NVivo 11 software $^{24}$ to assist with data coding and editing of the emerging codebook.

Table 1. Observation schedule topics and questions to observer.

\begin{tabular}{ll}
\hline Topic & Questions to observer \\
\hline Attendance & How many people? Who's present? Who's missing? \\
\hline Patient queue & $\begin{array}{l}\text { Describe a few patients discussed today, in particular success or failure stories. Who presented the patient? } \\
\text { How? What next steps were identified? How did team members react to the patient story? }\end{array}$ \\
\hline Decisions around the IBD Home process & $\begin{array}{l}\text { What process issues were discussed? What decisions were made? Was a point person identified to carry out } \\
\text { these new process decisions? }\end{array}$ \\
\hline Changes in team meeting & What was surprising or out of the ordinary in today's meeting?
\end{tabular}

Table 2. GRITT Team Interview Guide: topics and sample questions.

\begin{tabular}{|c|c|}
\hline Topic & Sample questions \\
\hline Program start & Can you describe some of the first meetings? Who was present? \\
\hline Current state of program & $\begin{array}{l}\text { What do you like about the team meeting? Is there anything you would like to change? How do you decide } \\
\text { which patients need to be discussed in the meeting? When do you mention IBD Home to patients? E.g. } \\
\text { during visit, after conferring with a colleague }\end{array}$ \\
\hline $\begin{array}{l}\text { Decision making about the IBD } \\
\text { Home processes }\end{array}$ & $\begin{array}{l}\text { How are decisions about the processes for the IBD Home usually made? Do you participate in decision } \\
\text { making? Give some examples. }\end{array}$ \\
\hline Patient stories: successes and challenges & $\begin{array}{l}\text { In your opinion, what is the impact of the IBD Home program on patients? Can you give some examples of } \\
\text { success stories about patients who got better because of IBD Home? Were there any disappointing cases? } \\
\text { How do you handle disappointment as a team? }\end{array}$ \\
\hline Impact on provider wellbeing & $\begin{array}{l}\text { How, if at all, has the program affected your daily work? Do you think burnout is common in your field? } \\
\text { What do you do to prevent burnout? }\end{array}$ \\
\hline
\end{tabular}

Table 3. Gastroenterologist Interview Guide: topics and sample questions.

\begin{tabular}{ll}
\hline Topic & Sample questions \\
\hline $\begin{array}{l}\text { Introduction to the IBD } \\
\text { Home program }\end{array}$ & How did you learn about the IBD Home program? What was your first impression of the IBD Home program? \\
\hline $\begin{array}{l}\text { Current interactions with IBD } \\
\text { Home team }\end{array}$ & $\begin{array}{l}\text { Have you referred patients to the program? If so, how do you decide when/ which patients to refer? Can } \\
\text { you give an example of a patient you referred to the IBD Home? How do you describe the program to your } \\
\text { patients?What happens after a referral? Have you seen any impact of the program on your patients? Please } \\
\text { describe. }\end{array}$ \\
\hline Burnout & $\begin{array}{l}\text { Do you think burnout is common in your field? Do you think the IBD Home program impacts your workload? } \\
\text { How? }\end{array}$
\end{tabular}




\section{Results}

We interviewed 17 people in total, including 11 members of the IBD Home team and 6 referring gastroenterologists (Table 4). Weekly team meetings $(\mathrm{N}=9 \pm 3$ ) included behavioral health providers, nurse practitioners, nurses, dietitians, a clinical pharmacist, and clinical coordinators. Other roles included a child life specialist and a population health researcher. Physicians referred patients with psychosocial comorbidities such as depression and anxiety to the IBD home. Initially the team enrolled all referred patients. Later, they developed exclusion criteria and a patient complexity score to manage the volume. Some providers reported increase in their workload (social work, nutrition) while others' workload was unaffected (gastroenterology, nursing). No physicians attended team meetings regularly. Below we discuss team building and leadership, patient selection for the medical home, weekly team meetings, the patient complexity score, and the impact of the program on health care providers/ members of the multidisciplinary team.

\section{Team Building and Leadership}

By team building and leadership, we mean to capture what we observed in the team meetings with some consistency and what team members said about their subjective perception of their team (e.g. who was in and who was out of the team, who led team meetings and who coordinated the work of the team outside of the meetings). According to our observations, which our participants confirmed, it was helpful for the team leader to have autonomy in making hiring and firing decisions. This enabled the selection of team members with the personalities and skill sets to match the unique needs of the patient population the IBD Center serves. According to one team member,

Table 4. Total respondents by role.

\begin{tabular}{ll}
\hline Role & \# of Personnel (N = 17) \\
\hline Psychologist (PhD) & 1 \\
\hline Social Worker (MSW) & 1 \\
\hline Dietitian (RD) & 2 \\
\hline Nurse (RN) & 2 \\
\hline Nurse Practitioner (NP) & 2 \\
\hline Health Population Specialist (MS) & 1 \\
\hline Clinical Pharmacist (PharmD) & 1 \\
\hline Child Life Specialist (CCLS) & 1 \\
\hline Gastroenterology Attending (MD) & 4 \\
\hline Gastroenterology Fellow (MD) & 1 \\
\hline Resident (MD) & 1
\end{tabular}

....as far as the different services that have been provided to the patients... [the psychologist] started those as soon as she came here, so the GRITT program was like the unofficial [name] program, but as soon as [the psychologist] came here and was doing hypnotherapy, and then she hired [the social worker]. She hired... all of us. [... ] Pretty much everyone on the team. And through our interviews she kind of... tailored it to what she knew and our different skill sets.

The team leader described doing a listening tour when she first joined the institution.

I... went around the hospital and met with a bunch of different people and heard about their either medical home or their integrated [service]. So, I met with like the primary care medical home providers and their social workers and learned how they did it. I met with people basically around the hospital that had different roles at the systems level, just a listening tour. And then that started to give me a sense of what would be doable within the Sinai system, what I was hearing from them... [...] Things to avoid, how they were collecting data, whether they were using any kind of theoretical models...

Several team members reported that the team leader was "very open to receiving ideas and implementing [them]" and "supports everyone's passions," increasing team buy-in. For example, one team member described the team leader's style as follows:

I guess it's also having [the psychologist] be that team leader to constantly coach us on how the [IBD Home] format should be, and whether or not certain patients are eligible or not, and training us, while we're having these meetings, to be able to fine-tune how we do this was really important, in a very nonjudgmental way. Really just trying to give us the ability to talk about patients and seeing whether or not they were appropriate.

Leadership was also distributed so that several team members led the weekly team meeting on a rotating basis when the founding team leader was away or unable to attend. One team member thought the team leader "needs to be around more" but added that "we do fine when she's not there, too. We know what has to get done because we've been doing it for a while."

\section{Patient Selection}

By patient selection, we mean to document the informal criteria the team applied to patient cases in weekly meetings and their accounts of how these criteria evolved 
over time. Initially the GRITT team accepted all IBD patients referred to the program. However, the team reported that patients that refused to engage with care caused frustration among staff potentially leading to burnout. To combat this problem, the team began discussing a stricter set of criteria for enrolling or rejecting proposed patients from the program. At that point, the team agreed to focus on highly complex patients, typically presenting with a combination of active IBD symptoms and psychosocial issues such as depression or anxiety. The team would reject ("GRITT-ject") some patients referred to the program for the following reasons: i) patients did not want to be part of the program; ii) had no active IBD symptoms; or iii) had psychiatric problems beyond the scope of IBD therapists. The team also removed patients who consistently failed to engage with the program and their providers after being enrolled. According to one team member, "setting boundaries around what the team was willing to work on and what they weren't [was very important]." This was different from most medical homes, in which neither providers nor patients have a choice. There are certain criteria, and if the patient meets these criteria, they are enrolled, even if they never make a single appointment. The team decided that they "weren't taking in help rejecters. Because that's not a good use of resources. One, because the patient is still going to continue with nonadherence to treatment. But two, the team... people are burned out by help rejecters." A team member ordered a "GRITT-jected" stamp for each member of the team, and the term was used throughout subsequent meetings as a lighthearted way of giving back control of the patient queue to the team members. This enabled the team to focus on patients that would benefit from a high-touch approach and prevent provider burnout.

\section{Weekly Team Meeting}

This theme describes weekly team meetings in terms of their composition, goals and achievements. The weekly team meeting played an integral role in the GRITT program, enabling interprofessional learning, team bonding, and multidisciplinary discussions of how to approach particularly challenging cases. One team member commented:

I am really surprised at how well maintained and consistent it has stayed. I mean, I guess we should attribute that to [the psychologist] because our Thursday meetings are consistent. And even if she wasn't in the office, she would say these meetings should continue. So that consistency really helped to build, I think, the longevity and also credibility of the program, both to us, the people involved, but also to the [physicians].

The meeting was never mandatory, but the team members (average of 9 people) voluntarily attended it on a weekly basis and emailed the team leader if they were un- able to attend. Several team members described team meetings as "fair" and "collaborative." One team member elaborated: "I think the group gets along really well, and the goal really is for the patients, and everybody seems to care about it, and care about them." The meetings have transformed from a "general discussion" to "very organized in terms of [discussing] psychosocial, nutrition, all the medical needs." According to one participant who was there at the start of the medical home:

Initially... [th]ere wasn't really as much organization as there is now... we would just... think of patients that needed the home and just... have an open discussion about it and what their needs were, and... assign people to follow up with them. But now it seems to be more regimented. [...] We know which team players have to meet with the patients to address which needs. [...] ...there's a whole systematic approach to it.

Even in this structured format, there was still some room for levity, as a team member explained, "there's a lot of humor and jokes... When we leave here, we are dealing with other people's anxieties... we have to have a place where we can just... make some light of it." This allows people to "blow off steam and bond together" according to another team member.

Some team members wanted the team discussion to be more focused and efficient, expressing frustration with the pace of some meetings: "there could be meetings where we only get through two patients, and we could get through 20." According to our observations, the number of patients discussed in each meeting varied between 1 and 15 , with an average of 8 patients per meeting. This number usually included an average of 3 new patients considered for enrollment and updates on 4-5 patients enrolled in the SMH. Given that the meetings rarely lasted longer than an hour (sometimes up to 75 minutes), this means the team discussed each patient for under $10 \mathrm{~min}$ utes on average. In practice, this varied greatly. For example, in one meeting the team discussed a pediatric patient who was in crisis, and did not discuss any other patients that day. According to our observations, the number of patients discussed varied depending on who was leading the meeting. Some team members encouraged detailed conversations, "a deeper dive" into one or two cases, whereas others facilitated transitions to the next case once a care plan was set.

\section{Patient Complexity Score}

This section summarizes the development of the patient complexity score from the participants' perspective. Determining a precise set of entry criteria has proved challenging and the team discussed potential candidates on a case-by-case basis. About six or seven months into the program, the team developed an integrated patient 
complexity score that helped streamline decision making. One of the team members described the program before the score, "it was more like an ideology, I guess, of [name of program]." The patient complexity score included a set of criteria in five domains (general health, nutrition, resilience, independence, trouble with the health system) with a total score ranging from 0 to 100 (100 signifying optimal health). Selecting a maximum score of 100 was intentional to simplify scoring and interpretation based on the grading numerical scale in which " 100 is good and zero is bad." A combined score of 70 and below was used as a cutoff for enrolling a patient into the program. Our respondents reported striving for simplicity because there was concern a complex scoring system could "burn out their providers really quickly." The team leader and the population health analyst led the development of the score, utilizing recommendations from relevant team members for each domain (e.g. nurses commented on the general health domain, a dietitian helped develop the nutrition domain). For example, one team member described how she helped create one of the sub-scores: "I basically looked at many different scoring methods [...], but then I adjusted it to our patient population, made it outpatient population and gastroenterology related." The patient complexity score functioned as a communication tool to focus the team on important domains that had to be considered and bring them to consensus on the care plan for the areas with the lowest scores.

Initially, the entire team would score patients during weekly meetings. Several scoring sessions were held to help "catch up" with scoring of the previously enrolled patients. About one year into the program's existence and 6 months after developing the patient complexity score, each provider scored patients independently in the domain most relevant to their expertise (e.g. the dietitian scored the nutrition domain). Several team members stated that they wished the scoring system was more automated, with a system that calculated the weight of each category and output a score in order to reduce human error. Two years after the program started, there were between 100 and 150 enrolled patients in any given week and between 150 and 200 graduated, GRITT-jected, and removed patients.

\section{GRITT Impact on Providers}

In the impact on providers theme, we summarize participants' perceptions of the impact of their participation in the medical home on their workload, professional and personal growth and well-being, and the risk of burnout. Team members reported several benefits of being involved in the GRITT program and participating in weekly team meetings, including interprofessional learning and collegiate support. Team discussion "allow[ed] me to learn what other disciplines do in order to help that patient... so I develop more skills", stated one team member. Another emphasized that "it makes me feel good about my job because we get to talk about the positive progress in people." Without the weekly meetings in which colleagues provided updates on patients, health care providers would not normally hear from the patients who are doing well. According to one respondent, "you're only focusing on... the sickest people in your cohort... [which can feel] discouraging at times... and you forget how many people you're only seeing like twice a year who are functioning very highly."

Burnout is a common problem in human services in general and in health care in particular. Our respondents admitted that working with a large volume of medically and psychosocially challenging patients is difficult and "there's always somebody that is... getting burned out." According to our interviewees, weekly meetings helped build trust among group members who could "talk to each other [outside of the meeting] and seek support that way." This usually took place outside the confines of the regular meeting on a one-on-one basis. One respondent explained that having support of a multidisciplinary team who work with the same type of patients was "very protective from burnout": "you're... with people who, even if they don't have the same letters behind their name, really... are doing the same work." In addition to collegiate support, several team members have taken steps to limit the number of patients they see in order to protect themselves against burnout.

\section{Discussion}

According to our participants and based on the observations of weekly team meetings, the core components of the successful development of a team within the medical home setting are autonomy in hiring and firing decisions to tailor the composition of the team, regular team meetings (e.g. weekly), and development of clear enrollment, rejection, and graduation criteria. The model we describe is similar to the established practices for addressing the needs of vulnerable high-need high-cost patients ${ }^{25,26}$ but also involves several important differences. Blumenthal and colleagues (2018) summarize evidence-based practices to improve care for high-need, high-cost patients: "i) targeting interventions to those patients who are most likely to benefit, ii) comprehensively assessing patients' needs, iii) employing trained care managers to facilitate coordination among care team members, iv) implementing supportive health information technology, v) promoting patient and caregiver engagement, and vi) partnering with social service providers to address patients' non-clinical needs." The SMH we studied, GRITTTM-IBD, organically over time established enrollment criteria that focused on the patients most likely to benefit from the interventions (e.g. non-adherent patients or those with several no-shows were removed from the program to preserve provider engagement). Patients' needs were comprehensively assessed in several stages: first during an intake over the phone after a referral was received, then in 
the weekly team meeting, and lastly offline between individual providers as necessary to adjust the care plan. The patient complexity score communication tool facilitated care plan development and agreement across team members. Thanks to the weekly GRITT meetings, team members were able to piece together key information about patients in crisis in order to identify their needs and best ways to address them. The inclusion of health care professionals from different disciplinary backgrounds (e.g. social worker, dietitian, clinical pharmacist) allowed provision of services to high-need, high-cost patients. In contrast with the established practices suggested by Blumenthal and colleagues, the SMH team we studied relied on in-person weekly meeting rather than the work of care managers to facilitate coordination across providers.

The development of IBD medical homes is a recent phenomenon and only a few have been described in the literature. ${ }^{10,27}$ At the University of Pittsburgh Medical Center, one of the largest such centers, metrics show that one third of IBD patients are responsible for three-quarters of expenditures, primarily during inpatient care. ${ }^{27}$ This sub-population of IBD patients is particularly prone to suffering from concomitant mental illness and limited social support and would therefore benefit most from a comprehensive, team-based approach involving extensive psychosocial and nutritional support that could reduce emergency room visits and hospitalizations. ${ }^{27}$ The SMH model is uniquely positioned to both improve patient outcomes and quality of life as well as reduce costs for the care of the most complex IBD patients. Our data support the possibility that medical homes may also benefit providers by being a source of collegiate social support that can help reduce burnout. Additionally, medical homes may help reduce healthcare fragmentation by enabling high-quality care throughout the lifespan in a single, cohesively organized setting. Effective collaboration and cross-training of the full spectrum of providers, including physician trainees, social workers, psychologists, nurses, pharmacists, and dietitians can help prevent future fragmentation. This collaboration was particularly evident during weekly team meetings, due to the protected time for team building and case management that occurred during the formative months in the beginning of the $\mathrm{SMH}$ we studied, GRITTTM-IBD.

Our study also has some limitations. For example, our observations are limited to a single IBD medical home with a unique patient population and providers that may not be transferable to other settings. This study was started about a year after the start of the program, preventing comparison of provider perspectives at the start of the program to their experiences at the time of the observations and interviews. Nonetheless, we believe our findings may be useful to other centers looking to develop a medical home for IBD patients if care is taken to elicit input from the team members during the development process. It is also possible that this research on IBD Home may be rel- evant to medical homes in other disciplines that involve specialty chronic disease management, such as rheumatology or endocrinology.

This study is unique in that the two qualitative researchers were embedded in the medical home team, which led to the lines between the researchers and the team members blur. This qualitative study created the safe space for a feedback loop between the team members and the team leader, with the researchers discussing the evolution of the medical home, its methods, and its goals regularly with the team. In this study, we used qualitative research methods in an applied manner. This marks a transition away from the traditional extracting nature of research towards an inclusive co-creation and co-team building with the input from anonymous interviews and systematized findings. Our institution recognized the innovative nature of this team building approach by awarding the multidisciplinary medical home team with a Dean's Healthcare System Team Science award in 2019.

Health care professionals aiming to build a medical home program could benefit from enlisting a qualitative researcher to collect ongoing feedback from their team. Qualitative researchers should pursue partnering with clinical teams to expand their understanding of the clinical perspectives. Ultimately, these collaborations can lead to more clinically relevant and better designed studies as well as theoretically informed and strategic program development.

\section{References}

1. Fox A, Reeves S. Interprofessional collaborative patientcentred care: A critical exploration of two related discourses. J Interprof Care 2015;29:113-8.

2. Clay MA, Sikon AL, Lypson ML, et al. Teaching while learning while practicing: Reframing faculty development for the patient-centered medical home. Acad Med 2013;88:1215-9.

3. Kirschner N, Greenlee C, American College of Physicians. The Patient-Centered Medical Home Neighbor: The Interface of the patient centered medical home with specialty/ subspecialty practices. American College of Physicians. Philadelphia, PA; 2010.

4. Gimm G, Goldberg DG, Ghanem N, et al. Provider Experiences with a Payer-Based PCMH Program. J Gen Intern Med 2019;34:2047-53.

5. Cronholm PF, Klusaritz H, Nguyen GT, et al. Resident Engagement in the Patient-Centered Medical Home. Fam Med 2016;48:603-12. Available from: https:/www.stfm.org/FamilyMedicine/Vol48Issue8/Cronholm603

6. Sklar M, Seijo C, Goldman RE, Eaton CB. Beyond checkboxes: A qualitative assessment of physicians' experiences providing care in a patient-centred medical home. J Eval Clin Pract 2019;25:1142-51. doi:10.1111/jep.13136

7. Loeb DF, Bayliss EA, Candrian C, et al. Primary care providers' experiences caring for complex patients in primary care: A qualitative study. BMC Fam Pract 2016;17:1-9. Available from: http://dx.doi.org/10.1186/s12875-016-0433-z

8. Huang X, Rosenthal MB. Transforming Specialty Practice 
- The Patient-Centered Medical Neighborhood. N Engl J Med. 2014;370:1376-9.

9. Itri JN. Patient-centered Radiology. Radiographics. 2015;35:1835-46.

10. Regueiro MD, McAnallen SE, Greer JB, et al. The Inflammatory Bowel Disease Specialty Medical Home: A New Model of Patient-centered Care. Inflamm Bowel Dis 2016;22:1971-80.

11. Sakshaug JW, Miller DC, Hollenbeck BK, Wei JT, Hollingsworth JM. Urologists and the patient centered medical home. J Urol 2013;190:1345-9.

12. Friedberg MW, Rosenthal MB, Werner RM, et al. Effects of a Medical Home and Shared Savings Intervention on Quality and Utilization of Care. JAMA Intern Med 2015;175:13628. Available from: http://archinte.jamanetwork.com/article. aspx?doi=10.1001/jamainternmed.2015.2047

13. Kirschner N, Barr MS. Specialists/subspecialists and the patient-centered medical home. Chest J 2010;137(1):200-4. Available from: https://linkinghub.elsevier.com/retrieve/pii/ S0012369210600347

14. Kruimel J, Leue C, Winkens B, et al. Integrated medicalpsychiatric outpatient care in functional gastrointestinal disorders improves outcome. Eur J Gastroenterol Hepatol 2015;27:721-7. doi: 10.1097/MEG.0000000000000335.

15. Friedberg MW, Schneider EC, Rosenthal MB, et al. Association Between Participation in a Multipayer Medical Home Intervention and Changes in Quality, Utilization, and Costs of Care. JAMA 2014;311:815-25. Available from: http://jama.jamanetwork.com/article.aspx?doi=10.1001/ja ma.2014.353

16. Koltun WA. Better together: improved care of the IBD patient using the multi-disciplinary IBD center. Expert Rev Gastroenterol Hepatol 2017;11:491-3. doi: 10.1080/ 17474124.2017.1309289

17. Szigethy EM, Allen JI, Reiss M, et al. White Paper AGA: The Impact of Mental and Psychosocial Factors on the Care of Patients With Inflammatory Bowel Disease. Clin Gastroenterol
Hepatol 2017;15:986-97. Available from: https://inkinghub. elsevier.com/retrieve/pii/S1542356517302793

18. Mikocka-Walus AA, Andrews JM, Bernstein CN, et al. Integrated models of care in managing inflammatory bowel disease: a discussion. Inflamm Bowel Dis 2012;18:1582-7. Available from: https://academic.oup.com/ibdjournal/article/18/8/1582-1587/4607736

19. Click B, Regueiro M. The Inflammatory Bowel Disease Medical Home: From Patients to Populations. Inflamm Bowel Dis 2019;25:1881-5. doi:10.1093/ibd/izz062

20. Regueiro M, Click B, Anderson A, et al. Reduced Unplanned Care and Disease Activity and Increased Quality of Life After Patient Enrollment in an Inflammatory Bowel Disease Medical Home. Clin Gastroenterol Hepatol 2018;16:1777-85. doi:10.1016/j.cgh.2018.04.007

21. Long T, Dann S, Wolff ML, Brienza RS. Moving from silos to teamwork: Integration of interprofessional trainees into a medical home model. J Interprof Care 2014;28:473-4.

22. Leasure EL, Jones RR, Meade LB, et al. There is no " $\mathrm{i}$ " in teamwork in the patient- Centered medical home: Defining teamwork competencies for academic practice. Acad Med 2013;88:585-92.

23. Hager K, St Hill C, Prunuske J, Swanoski M, Anderson G, Lutfiyya MN. Development of an interprofessional and interdisciplinary collaborative research practice for clinical faculty. J Interprof Care 2016;30:265-7.

24. Godau R. Qualitative data analysis Software: NVivo. Qual Res J 2004;4.

25. Blumenthal D, McCarthy D, Shah TB. Academic Medical Centers and High-Need, High-Cost Patients: A Call to Action. Acad Med 2018;93:1617-9.

26. McCarthy D, Ryan J, Klein S. Models of Care for HighNeed, High-Cost Patients: An Evidence Synthesis. Issue Brief (Commonw Fund) 2015;31:1-19.

27. Kosinski LR, Brill J, Regueiro M. Making a Medical Home for IBD Patients. Curr Gastroenterol Rep 2017;19:20. doi: 10.1007/s11894-017-0561-1 